Exploring the Oversight of Risk Management in UK Higher Education Institutions:

The Case of Audit Committees.

Teerooven Soobaroyen ${ }^{a}$, Collins G. Ntim ${ }^{\text {, }}$, Martin J. Broad ${ }^{\text {b }}$, Dila Agrizzia ${ }^{\mathrm{a}}$, Krishanti Vithana ${ }^{\mathrm{b}}$

\author{
${ }^{a}$ Essex Business School \\ Essex Accounting Centre \\ University of Essex \\ Colchester, UK
}

${ }^{b}$ Department of Accounting

Southampton Business School

University of Southampton

Southampton, UK

- Corresponding author. Address for correspondence: Essex Business School, University of Essex, Wivenhoe Park, Colchester, CO4 3SQ, UK. Tel: +44 (0) 1206 874015. Email: tsooba@essex.ac.uk

We acknowledge the financial support of the Leadership Foundation for Higher Education (LFHE) Small Development Project Scheme. We would also like to thank the reviewer and participants of the $8^{\text {th }}$ Asia-Pacific Interdisciplinary Research in Accounting (APIRA) Conference (Melbourne, July 2016) for their valuable comments and suggestions. 


\title{
Exploring the Oversight of Risk Management in UK Higher Education Institutions: The Case of Audit Committees.
}

\begin{abstract}
We explore how audit committees (ACs) oversee risk management in UK Higher Education Institutions (HEIs), using semi-structured interviews, attendance at $\mathrm{AC}$ meetings and documentary analysis. We find that the AC's oversight seems constrained by a fixation on the process of risk management, an over-reliance on risk registers, and varying levels of emphasis on operational risks. Theoretically, the AC's oversight reflects different shades of symbolic and substantive activities designed to maintain the HEI's legitimacy and that of its governing board, hence providing a symbolic representation. We raise concerns as to the AC's ability to monitor effectively the HEIs' risk management practices.
\end{abstract}

Keywords: audit committee; risk management; governance; higher education.

\section{Introduction}

This study examines the role of corporate governance structures in UK higher education institutions, with a particular emphasis on the oversight of the institution's risk management function by the audit committee (AC). Higher education institutions (HEIs) have continued to witness fast-paced changes worldwide, mainly because of changing expectations and demands by societal actors and stakeholders. Higher education (HE) reforms and policies, such as those related to cuts in public funding, the greater involvement of industry in the production of research and knowledge, the positioning of higher education as an 'economic' service or 'export-oriented' sector (e.g., international student market), and a private-sector led regulatory mind-set of the State, have also led to the corporatisation of the HEI sector (Parker, 2011; Soobaroyen et al., 2014; Ntim et al., 2017). An important organisational implication of these corporatisation reforms has been the gradual embedding of 'corporate governance' (Parker, 
2011; Ntim et al., 2017) within the decision-making structures at the apex of HEIs (typically referred to as University governing boards or councils). Yet, little is known about the processes and/or consequences of these private sector-inspired reforms in the HEI sector (Christopher, 2012; Greatbatch, 2014).

We focus on the audit committees of UK HEIs and how they monitor the risk management function for the following reasons. First, many of the governance reforms, including those relating to the $\mathrm{AC}$ and risk management (CUC - Committee of University Chairmen, 2008, 2009; LFHE, 2009), have been initiated in the UK (Shattock, 2013; Taylor, 2013) and disseminated worldwide (Parker, 2011). The introduction of good governance codes for non-executive governors (CUC, 2009), AC members (CUC, 2008), and risk management (HEFCE- Higher Education Funding Council for England, 2001, 2005) are key examples of the application of the new public management (NPM) concept in UK HEIs (Power et al., 2009; Parker, 2011). Secondly, UK austerity policies have led to funding cuts of approximately $29 \%$ in the HEIs' budget, and fostered the gradual implementation of a 'free/quasi' marketised HE sector. The introduction of direct competition into the HE sector has, in particular, increased operational complexity, uncertainty, and a scramble for (arguably) risky investments (e.g., large scale expansion of teaching facilities; transnational education activities, such as foreign campuses or outposts) using debt and in the name of ensuring 'growth' (Parker, 2013; Marnet \& Soobaroyen, 2018; Ntim, 2018). Thirdly, the new 2017 UK Higher Education and Research Act advocates further neo-liberal reforms in the sector, amidst concerns about the viability of the student loan scheme and the rising costs of HE operations (including staff pension).

Overall, the long-term financial sustainability of the sector, and of its individual institutions, is in question. In this context, understanding how the HEI's risk management practices are monitored by governing boards or university councils (typically made up of a majority of non-executive members), becomes of practical and policy-level importance. 
Research-wise, the organisational function and practice of risk management has attracted significant attention (Spira \& Page, 2003; Arena et al., 2010). A relatively large stream of positivist and quantitative-led studies has examined the consequences of risk management practices (inclusive of disclosures) in the corporate sector (Cabedo \& Tiradao, 2004; Abraham et al., 2012; Greco, 2012). Similar to research that is concerned about the ability of audit committees (typically involving a majority of non-executive members) to monitor financial accounting aspects, there have been studies investigating statistical associations between AC characteristics and risk management practices (Linsley et al., 2006; Ntim et al., 2013; Ntim, 2018). By contrast, qualitative and recent studies offering in-depth insights on the monitoring and oversight role of audit committees have been less prevalent (Cohen et al., 2002; Gendron et al., 2004; Gendron \& Bedard, 2006), and even less so when it comes to the prevalence of risk management practices in private and public sector organisations ${ }^{1}$ (Collier \& Woods, 2011; Palermo, 2014). Distinctively, therefore, we contend that there is a dearth of in-depth research on how governance structures actually monitor or oversee the risk management function (i.e., governance practice of oversight and monitoring). This specific task of ensuring that an appropriate and effective risk management system is in place within the organisation is typically a part of the audit committee's mandate. Informed by the challenges facing the UK HEI sector and the growing role of risk management in addressing the latter, we formulate our two research questions: (1) How do audit committees, as a part of university governing boards, monitor organisational risk management practices? and (2) How effective is the monitoring and oversight of the risk management practices in HEIs?

Consequently, the objective of this study is to investigate and analyse the role of the audit committee $(\mathrm{AC})$ in the monitoring of the HEIs' risk management practices. We conducted interviews with senior executive and non-executive leaders of HEIs (e.g., AC chairpersons, AC

\footnotetext{
${ }^{1}$ Indeed, much of the audit committee literature (Gendron et al., 2004) is concerned with the AC's impact on observable outputs (e.g. quality of published earnings; financial disclosures) and the implications for financial market participants. Arguably, these can be seen to be less crucial for institutions such as universities or not-forprofit organisations.
} 
members, finance directors and senior internal auditors). We were given permission to attend and observe $\mathrm{AC}$ meetings in order to gain an understanding of how $\mathrm{AC}$ members seek explanations from managers on the issue of risk management and had sight of relevant documentation (e.g., risk registers and review reports by internal/external auditors). We find that the AC's oversight of risk management largely involves a symbolic monitoring of processes and ensures that 'loops are closed' (and appropriately represented on the risk register). By contrast, our findings reveal that there is little in the way of substantive improvements by the ACs investigated in addressing operational and strategic risks. Theoretically, we draw upon institutional and legitimacy-based notions of symbolic and substantive management strategies (Ashforth \& Gibbs, 1990) to argue that the AC's risk oversight process involves a blend of concrete actions (e.g., questioning risk owners and reviewing risk register) and symbolic acts (e.g., focus more on operational or peripheral risks and less on strategic risks, process-driven oversight, limited ability to strengthen the monitoring of risk management and mitigation activities, and ensuring compliance).

In doing so, this paper extends the limited, but gradually emerging qualitative evidence that allows researchers, practitioners and policy makers to peer into the 'black box' of the audit committee (Gendron et al., 2004; Turley \& Zaman, 2007; Bailey \& Peck, 2013). Furthermore, the findings contribute to the largely descriptive evidence on the adoption of audit committees by UK HEIs (Dewing \& Williams, 1995) and to the recent insights by Christopher (2012) on the interplay between risk management and internal audit functions in Australian universities. Lastly, the resulting analysis points to the limited 'monitoring' reach of the AC structure in the HEI sector, and in effect, questions the AC's ability to ensure that an effective risk management system is in place. Other than providing 'micro-level' evidence to underpin the criticisms (and outcomes) of university corporatisation (Parker, 2011; 2013), these insights are a matter of concern for HEI regulators and outside stakeholders, who might expect greater levels of 
engagement with, and monitoring of, such an important issue in an increasingly turbulent environment (Schofield, 2013; Ntim, 2018).

The remainder of this paper is organised as follows. The next section discusses the institutional framework for risk management and governance in UK HEIs and relevant research evidence. The following sections present the theoretical framework and its relevance to AC research, the research methods, empirical findings, and overall discussion. We conclude it with a summary of our research contributions, implications and avenues for further research.

\section{Risk management and oversight in UK HEIs: Policies, practice and research evidence}

With specific reference to the role of the $\mathrm{AC}$, as a governance/oversight mechanism and the adoption of risk management systems, as an organisational practice, we outline three main HEI documents, namely: (i) the 2009 CUC governance code for governors; (ii) the 2008 CUC code for AC members; and (iii) the 2005 HEFCE risk management practice guide. First, the 2009 CUC governance code broadly spells out how UK HEIs should be governed and covers a wide range of issues, such as management conduct, strategic planning, accounting and finance, auditing, estates management, human resource management, equality and diversity, and health and safety. Although the code places the overall responsibility for maintaining sound practices at the governing board level, the AC is mandated to actively identify, advise, manage, monitor, review and report on risks that the institution faces.

Furthermore, the code identifies essential elements of the oversight of risk management, namely: (i) an effective review by independent governing board, finance, and ACs; (ii) an effective internal control systems that consist of policies, processes and procedures, objectives and plans, and management of risks and opportunities; (iii) an effective monitoring of financial and operational performance, physical safeguarding of assets, separation of duties, and authorisation and approval procedures; and (iv) an active identification and management of all business risks. The code also emphasises the need for the appointment of independent and 
effective external and internal auditors, supported by good information systems. Finally, the code highlights the importance of addressing risks that may arise from adhering to the requirements of funding councils, and those in relation to procurement and value for money. In a similar vein, the 2008 CUC code for members of ACs discusses at length the specific roles that ACs can play in the oversight of HEI risk management. Five important issues are highlighted, namely: the AC's responsibility for ensuring that a sound risk management system is in place; what ought to be the components of a risk management system; the process for reviewing the system; the timing and procedures for the AC's regular and annual reviews of institutional risks; and the preparation of an $\mathrm{AC}$ annual report for the governing board/regulators.

Lastly, the 2001/2005 HEFCE and 2009 LFHE (Leadership Foundation for Higher Education) good practice guides to risk management in UK HEIs provide guidance on the definition, identification, classification, categorisation, and specific practical examples of risks that a HEI may face, including their contributing factors, early warning control mechanisms and mitigating actions that may be taken to manage them. In particular, the $\operatorname{HEFCE}(2001,2005)$ documents cover a wide range of risk management issues and offer a self-assessment checklist of good practices for ACs. There is a strong emphasis on the maintaining of up-to-date risk registers by corresponding risk owners, in relation to the following: (i) information (risk type, description, consequences, rating in terms of likelihood and impact, controls and actions for improvement); (ii) categorisation (new, enduring, challenging, dying, dead and re-emerging risks); (iii) strategic approach to control (top-down, bottom-up and integrated); (iv) rating/'traffic light' reporting (red, amber/yellow and green); (v) appetite in terms of exposure (high, medium and low); and the use of a matrix to present risk findings (risk profile, likelihood and business impact). A list of 51 practical examples of significant risks that fall under eight broad categories ${ }^{2}$ is provided to guide HEI managers.

\footnotetext{
2(i) reputation (5 items); (ii) student experience (6 items); (iii) staffing (4 items); (iv) estates and facilities (7 items); (v) financial (11 items); (vi) commercial (5 items); (vii) organisational (7 items); and (viii) information and IT (6 items).
} 
Although there appears to be a great deal of sector-based guidance, there is scant evidence on how the above requirements have been implemented by HEIs and/or are monitored by the AC. For instance, Dewing and Williams (1995) studied ACs in UK universities using a questionnaire survey of 87 university finance directors. Although they revealed that $90 \%$ of the UK universities had established an AC with the primary task of securing internal and external accountability, the risk oversight task was not reported as an important role for ACs. A rare study of UK HEIs by Power et al. (2009) outlines how 'reputational risk', mainly expressed in terms of research metrics and league tables, appears to have become a key organisational concern as a risk to measure, manage and demonstrate accountability for; while at the same time marginalising the substantive factors that would enhance reputation. Furthermore, while the HEI-related guidance only documents 'reputational risk' as one type of risk, Power et al.'s (2009) analysis suggests that reputation has become a pervasive aspect in all discussions about risk management. More generally, risk management has come to embody an integrative narrative for universities, rather than being an instrument for coordinated actions and strategies.

Furthermore, Christopher (2012) investigated the extent to which the internal audit function can act as a governance control mechanism with a mandate to evaluate risk management practices. Based on interviews with nine vice-chancellors (VC) in Australia, his findings suggested that the VCs generally agreed that the internal audit function played an important governance and risk management role although significant challenges relating to corporate culture, access to resources and availability of qualified staff, were highlighted. More recently, Ntim (2018) investigated the level of risk disclosure in a sample of 117 UK HEI annual reports from 2009 to 2014 and found that the level of risk disclosures (particularly for operational and strategic risks vs. financial risks) was relatively low (compared to the corporate context), albeit slowly increasing in the later periods. While Ntim (2018) argues that the findings point to a lack of engagement at the institutional and governing board levels, and makes 
a number of recommendations thereof, there is little appreciation of, why the AC appears to be not so 'engaged'.

In conclusion, although the above studies are relevant in terms of the research context, none of them, specifically examined how ACs oversee the risk management function and what could possibly explain an apparently low level of engagement, as highlighted recently by Ntim (2018). We, therefore, consider a theoretical framework informed by institutional theory and the concepts of legitimacy and legitimation in the next section, in a bid to conceptualise an understanding of the AC's oversight of risk management and to draw from additional evidence outside the HE sector.

\section{Institutional theory in risk management}

The starting point, and support for, an institutional theory-led analysis is as follows. Drawing on Power (2004) and Parker (2011), we contend that the rhetoric of neo-liberalism and new public management in public and non-profit sectors has led to pressing demands for greater accountability and transparency, ostensibly with the aim of making organisations and decision makers more responsive to the demands and expectations of stakeholders. Most public and nonprofit bodies - such as UK public universities - have a multitude of key stakeholders/funders and no clear owner per se. They are often regulated and/or funded, at arm's length, by state agencies, that are themselves prone to different priorities, arising from political 'diktats' or funding initiatives. Furthermore, due to the multiple roles assigned to HEIs and the demands from different societal constituents, a key characteristic of HEIs lies in the 'production' of multiple outcomes and outputs that are imbued with moral, normative and often politically motivated imperatives (e.g., generating well-educated citizens and employable individuals, widening access and promoting social mobility, producing impactful research, and disseminating knowledge). These are inherently difficult to conceptualise and measure over a given period. Even when metrics are developed (e.g., research rankings and employability 
ratios) and become institutionalised over time, they remain problematic due to the difficulties in apportioning blame or praise as a result of a given practice or decision. In such a context, we would agree with Power's (2004) view that the risk management function has the potential to encompass even more events and activities as individuals become more aware, or are pressured to be aware, of the multi-faceted nature of the risks faced by the institution. Yet they are less clear as to how to quantify and/or address the uncertainties underlying these risks (Power, 2004).

According to Collier \& Woods (2011, p.113), institutional theory is predicated on the need for organisations to be seen as legitimate in the eyes of society in general and from the point of view of specific (and often powerful) societal actors. Should the organisation fail to retain its legitimacy, it will most likely lose financial, legal and social support (Scott, 1995). In this respect, part of this legitimacy-seeking behaviour involves the adoption of formal structures and practices that are considered to be appropriate and necessary. DiMaggio \& Powell (1983) contended that a process of isomorphism would ensue, whereby different institutions facing the same pressures (i.e., from funding or regulatory agencies) will adopt similar features and practices, such as a risk oversight process, a risk management policy, the regular reporting of risk management activities or other related practices (Ntim, 2018). A first implication from this analysis was that "...the adoption of an innovative measure may have little or no effect on the actual efficiency of organizational operations; its adoption fulfils symbolic rather than taskrelated requirements" (Tolbert \& Zucker, 1983, p. 26). Power (2004) and Collier \& Woods (2011) conclude that risk management tends to be simply a box-ticking exercise. Power (2004) also argued that the ultimate objective of risk management by governments, regulators and public bodies may not be so much about addressing the primary risks (such as a fall in student recruitment numbers), but rather, it may be about managing the secondary risk (threat to organisational legitimacy and reputation); arising from a perception that there is no risk management policy in place to address a fall in student recruitment. 
Relatedly, it needs acknowledging that an institutional theory perspective to the 'oversight' process of corporate governance has previously emerged in the literature (e.g., Cohen et al., 2007; Soobaroyen \& Mahadeo, 2008; Beasley et al., 2009). Governance structures, such as ACs, help "fulfil ritualistic roles that help legitimise the interactions among the various actors within the corporate governance mosaic" (Cohen et al., 2007, p.11), and these symbolic displays of accountability in turn enable the organisation to derive and maintain legitimacy. Thus, if one considers legitimacy to be a key organisational resource (Suchman, 1995) to be pursued by the organisation, then it is possible to view symbolic acts of oversight or monitoring to be as important as substantive or task-related ones in gaining or maintaining legitimacy.

In seeking to explain the legitimation process, Ashforth \& Gibbs' (1990) work is useful in terms of classifying activities, strategies and structures that organisational actors, such as governing board members, AC members and managers, can adopt to maintain or gain organisational legitimacy. First, actors and organisations adopt 'symbolic' practices (i.e., rituals, rhetoric and ceremonial events), which can involve being engaged in superficial activities on how organisational risks are governed and/or managed, with a view to appear to be consistent with social values and expectations (Ashforth \& Gibbs, 1990). Examples of such actions are the public espousal of socially acceptable goals, denial and concealment, redefining means and ends, offering accounts and apologies, and ceremonial conformity. Beasley et al. (2009) also argued that ceremonial actions are only 'loosely coupled' with the intended organisational goals, and are not significantly associated with organisational or governance effectiveness.

Second, organisational actors may engage in substantive management, whereby real and material changes in goals, structures, processes or socially institutionalised practices are enacted (Ashforth \& Gibbs, 1990). A key element of substantive management is that concrete actions have been performed in the organisation (Day \& Woodward, 2004), yet with the underlying motive of enhancing the legitimacy of the process and of the organisation itself. This encompasses role performance (e.g., in-depth analysis of risk reports and questioning of 
executives for $\mathrm{AC}$ members, from a monitoring or supporting perspective), conformance to rules and regulations, altering resource dependencies, and seeking to challenge the acceptability of socially institutionalised practices.

Thus, in contrast to Beasley et al. (2009), we do not contend that acts deemed substantive necessarily reflect different, and mutually exclusive, theoretical motivations such as those related to resource dependence or agency perspectives. Instead, we agree with Ashforth \& Gibbs' (1990) view that the organisation and their actors will typically draw upon a wide variety of practices and processes that will "shade greyly from the substantive to the symbolic" (p.181) in order to secure or gain legitimacy. In the HEI and AC context, we argue that the mix between the symbolic and substantive oversight of risk management will vary according to the profile of the AC members, their perceived role in HEI governance, the perceived extent of regulatory pressure pertaining to the organisation, and the extent of the relationship between the nonexecutive AC members and the HEI executives responsible for the risk management functions.

\section{Methodology}

This research formed part of a broader study examining the role and effectiveness of ACs in HEIs (Soobaroyen et al., 2014), whose initial trawl of secondary data (annual reports) highlighted notable variations in the level of disclosure, including risk disclosures. As part of the study, we contacted 15 universities (either via the AC Chair or the Secretary of the Governing Board), from a diverse cross-section of UK HEIs, including large/small, research-/teachingintensive, different mission groups, and different geographic regions, to request for their participation in an in-depth study of their ACs. In spite of several reminders, nine did not respond or declined to participate, primarily due to lack of time and workload reasons. Only six institutions responded positively and they were from Wales, Scotland, and different regions of England, including London. Their size differed greatly, ranging from a minimum total asset (and annual income), respectively, of $£ 230 \mathrm{~m}$ ( $£ 118 \mathrm{~m})$ to a maximum of $£ 2 \mathrm{bn}(£ 700 \mathrm{~m})$. 


\subsection{Methods}

We adopted a semi-structured interview approach to allow for comprehensive conversations with participants. Accordingly, we relied on a set of open-ended questions (Decoy, 2017; Miles et al., 2014). This amalgamation provided us with some degree of structure, while allowing latitude to use a personally engaging style of asking and sequencing the questions for different participants and according to the flow of the interview (Miles et al., 2014). Additionally, as is the case for semi-structured interviews (see appendix 1 for indicative questions), there was a possibility of looking for clarification or encouraging a follow-up (e.g., example) from interviewee answers. Our aim was thus to capture the participants' experiences, perceptions and understanding of the role of the $\mathrm{AC}$, as well as the issues and practices related to how risks were governed and/or managed within the institutions.

We interviewed 23 participants during 2013 and 2014. The interviews were taperecorded and its average duration was approximately 60 minutes. The transcripts were sent to the interviewees for a validation of their accuracy and completeness. The dates of the interviews were mostly determined by the dates of AC meetings, since non-executive board members tend to visit their institutions during such times. The interview dates for the other participants, namely finance directors and internal auditors, varied based on their availability. Table 1 summarises the position of the interviewees for each UK HEI (coded A to F) and the details of the meetings that members of the research team attended.

\section{Insert Table 1 about here}

The AC chairs and members interviewed were either working or had previously worked in private, government and/or the HE sectors, and they had variable levels of experience with AC activities. Two of the current finance directors joined the HE sector from private and public (non-HEI) sectors and, therefore, they were able to provide useful contrasts and insights on how ACs operated in their previous private and public sector organisations. Interestingly, none of the 
$\mathrm{AC}$ chairs had an explicit accounting/auditing/financial qualification and/or formal training in risk management. However, they gained some familiarity with accounting/audit and particularly risk management practices: as a result of previous work experience in financial services, law, business and local government, and also by occupying positions, such as AC/board member in a company, public body or charitable institution, and/or in senior managerial capacity.

An important aspect to highlight is that most UK HEIs have a 'finance committee', as part of the governance structure, which is normally tasked with the assessment and approval of financial plans, budgets and other significant projects, inclusive of any risk management-related reviews. The finance committee is typically dominated by members of the senior (executive) management team and by extension, incorporates fewer non-executive governing board members. Moreover, its remit/role is not regulated by HEI corporate governance guidelines (except for the expectation that a governing board member cannot occupy positions in both the audit and finance committees). In effect, an HEI's finance committee can be considered to be a branch of the executive, with some level of input and oversight by the governing board that is considerably less than what is observed in the case of an AC composed (fully) of non-executive members. Finally, the internal auditors also operated under different arrangements (i.e., in-house department, outsourced to a 'Big 4' audit firm or 'non-Big 4' one).

We employed the complete observer (non-participatory) approach to observe the three AC meetings (refer to Table 1) that we were allowed to attend (Saldaña, 2013; Baker, 2006; Mulhall, 2003). Two members of the research team attended each meeting. The objectives of our study were communicated to all participants before the AC meetings in accordance with research ethics conventions. The researchers' written notes of meetings were drafted independently during the meeting and compared thereafter for key commonalities and differences (e.g., focusing on process, dialogue and non-verbal aspects) (Saldaña, 2013; Mulhall, 2003). 
Finally, we analysed organisational documentation since it allowed us to gain further understanding of the role of the AC and institutional risk management practices (Patton, 2002). We were given access to a number of internal documents relating to the AC's work, including agendas, minutes of previous meetings, relevant board papers, risk registers as explained in section 2 and internal audit reports. These documents revealed valuable information, which helped us to gain further knowledge on governance and risk management in HEIs. Together with the other data collected, they represented an important part of the triangulation process, which allowed us to assess the consistency, as well as to understand the inconsistencies of the data that generated the results informing this study (Patton, 2002).

\subsection{Data analysis}

Drawing from the analytical techniques described in Parker \& Roffey (1997) and O'Dwyer (2004), and also informed by the coding strategies outlined in Miles et al. (2014), we recorded the initial themes from the interview data, identifying any commonalities or contradictions in relation to previous interviews or documentary evidence or from the notes gathered during our attendance at the AC meetings. In light of the relatively limited number of interview and documentary material, these stages of data processing, management and reduction, as well as examination of emergent themes were carried out manually.

Interview transcripts were read line by line to identify these initial themes, leading to the development of mind maps and open codes. Recurrent aspects raised by interviewees, and where relevant, documentation and notes from the meetings, were identified and used to develop multiple outlines of a 'big picture' (O’Dwyer, 2004). This process has been an iterative one as the authors re-assessed the initial themes and open codes from the transcripts, translating these into three core codes, relating to the oversight of the 'process' of risk management, the risk register as a primary representation of risk oversight and the selectivity of risks overseen by the AC. Subsequently, thick descriptions of the events and various elements of the 'big picture' are 
contextualised and analysed in relation to theoretical concepts of substantive and symbolic forms of oversight of risk management and their implications for organisational legitimacy.

\section{Empirical findings}

The above data analysis methods allowed us to present our data in relation to the research questions namely (1) How do audit committees, as a part of university governing boards, monitor organisational risk management practices?; and (2) How effective is the monitoring and oversight of the risk management practices in HEIs?. We subsequently discuss the findings.

\subsection{Oversight of the 'process' of risk management}

At the outset, it is important to note that all six institutions have a form of risk management system in place, albeit at different levels of 'maturation' within each institution (as explained subsequently). However, what became noticeable at an early stage was the fact that risk identification and resulting actions 'featured' deeply in the eyes of the governing board members when prompted to comment on their overall role within the AC.

"Well, I think it's the overall corporate governance role just because there is a tier of management running the University, obviously; and it's that sort of higher level of governance to make sure things are being done properly, make sure that it's financially sound, and make sure the data is correct and that sort of thing.... And risk management more broadly as well, to make sure that risks are identified and actually something is done about them. Lots of organisations don't see the real risks that are coming down the tracks towards them." (AM6)

"Well, the role of the Audit Committee I see as being comprised of four chunks really. One relates to risk management, the independent oversight of it, the second is the independent oversight of internal controls and governance, again on behalf of the Council. The third is to make sure that the arrangements for value for money are 
robust within the University and report accordingly to the Council, and the fourth is to ensure that there is data integrity provided, principally as far as it's provided to outside." (AC6)

These interviewees typically highlighted the relevance of their role in relation to risk, particularly to ensure that the institution's executives pay adequate attention to risk, without being themselves involved in the process of risk identification and risk management. Another AC chair, commenting on the interviewers' observation that the current membership did not include anyone with formal accounting qualifications, asserted that the role of the AC has 'moved on' from financial considerations and that:

"I mean we are alright at the moment, because audit isn't like it used to be-number crunching, it's much more about understanding governance and understanding risk, and risk management." (AC2)

From the discussions with other AC chairs and members, it was also observed that the AC's oversight of the institution's risk management policies mainly entailed an assessment of the process by which a risk was identified and addressed within the organisation. As such, this was less about the substantive nature of the risk itself. At the same time, the risk identified becomes a focal point for the AC members and an apparent trigger for 'organisational awareness', 'audit work' and demands for further accountability, as described by the following AC chair:

“It's an absolutely key plank of an audit committee's work to understand whatever those risks are, make sure that the internal and external auditors are aware of them ... ... so that we can pick out the key issues that might be facing the University. Research income is wrong, because we do not have the right numbers of people in different faculties reporting research income or allocating resources in the right way, and there's a big change to income as a result. Then that's significant and we need to make sure that the major items of risk to the University are covered in terms of the work we do and the work we commission from the internal auditors." (AC4) 
On the one hand, the above example reflects an awareness and concern with a central risk pertaining to the university's environment (research income success), which would lead to the 'deployment' of actions or strategies to mitigate the risk, and where required, commission in-depth work by the internal and/or external auditors. On the other hand, upon further discussion during the interview, it became clear that one $\mathrm{AC}$ chair (AC4) was not aware of the limits of any actions to address a largely 'un-controllable' outcome (success rates for research funding) and it was not clear whether additional audit work would be effective. Yet, the AC oversight process seemed to be somewhat 'duty bound' to investigate and delve further, particularly in response to the requirements set out in the various codes of practice.

Furthermore, given the relative lack of detailed expertise of most AC members in relation to the HE context, one relevant implication of the above process is that it was unclear whether $\mathrm{AC}$ members would be able to identify any omitted risks. In one case, we queried AC members on a very recent public announcement by the institution (A) that it will be launching a new (and admittedly risky) project ${ }^{3}$. Surprisingly, the AC members were unware of that (recently publicly announced) decision and, from their perspective, it remained unclear whether the current risk management process would have enabled the risks to be identified and recorded, or if so, when should they be included part of their risk oversight duties. In a different HEI (C), one member of the executive asserted that management was responsible for identifying the risks and presenting them to the $\mathrm{AC}$, and a particular reference to a 'lack of surprises' by the same interviewee, was suggestive of a strategy of showing a 'normal' picture of risks to the AC:

“... it is actually the executive's responsibility to produce this risk register; we [as in the AC members] can ask questions on it, but actually there aren't any surprises. There aren't surprising inclusions and there aren't surprising omissions from this register." (EX1)

\footnotetext{
${ }^{3}$ For the sake of confidentiality, we cannot reveal the nature of the project. However, it was a significant investment, which never generated substantial income and eventually was abandoned a few years after this interview.
} 
A good illustration of the role of the $\mathrm{AC}$ in terms of risk oversight was also put forward by a governing board member, who in the past held positions both as a chair of the finance committee and as an $\mathrm{AC}$ member:

"... the finance committee might want to be quite risky and innovative if you like. We might take a view that says, 'Right, in order to secure our future, we really need to invest heavily in the estate, and we are going to do that and we are going to draw down on loan and we are going to invest this, that and the other'. And we might take a view that the financial risk is worth it for the gain. And I think what the audit committee might want to check is, what are the consequences of those kinds of decisions, and would we be risking any other areas of our business by focusing on that kind of investment?" (AM5)

Whilst the above does somewhat provide an insight into the interface between the audit and finance committees and is suggestive of a collaborative approach to risk oversight by different governance structures, another AC member (AM2) with experience from the public sector had a different take on the matter. He compared the HEI context to that of public sector bodies that have a monitoring officer, who intervenes before a decision (involving a given risk) is taken, whereas in higher education:

“... that doesn't exist. It's a big gap, especially in institutions where they are working away from the role of a traditional registrar who could have been in its own way a monitoring officer or a finance officer, that could say, 'Hold on, rethink that'. Now instead of closing that gap, it seems to me that universities are at risk of going off in certain directions without having an opportunity for internal advice, to say, 'Is that decision wise? Is it correct? Have you followed procedures?' And because audit committee considerations are retrospective, they are unable to do that." (AM2)

An analysis of the role and responsibilities with regards to risk management and control - as defined by the HE governance code (Chapter 7, CUC, 2008) - indicates that the AC plays a crucial role (on behalf of the governing board) in establishing how key risks are identified, evaluated and managed, and in assessing the rigour and comprehensiveness of the risk review process (Section 7.3.1, p. 40). However, the concluding part of this section qualifies this role in 
terms of being a 'non-executive one' and, as such, it is one which 'only' requires the AC to satisfy itself that management has properly fulfilled its responsibilities. In our view, the interviewees' responses reflect a rigid emphasis on the oversight of the process of risk management rather than overseeing all aspects of risk management, such as the outcomes of risk management and decisions thereof. In doing so, and while there is evidence of a substantive examination of the risk management plans by the $\mathrm{AC}$, concurrently the AC's perceived role is limited to an assessment of the process and risks, initially instigated and identified by management, and by considering documentation on an a posteriori basis. To put it differently, the ACs do not appear to undertake a more rigorous assessment of organisational risks, prior to the decision(s) being taken by the university. The emphasis is instead on the risk once it is 'in place and recorded' and, therefore, the focus of the AC's work is very much guided by what is first recorded in the risk register.

\subsection{The risk register as the primary representation of risk oversight}

Notwithstanding that AC members appear to be well aware of their role with regards to risk management and that the relevant codes have been in force since 2008 , further interactions revealed that the time and extent to which $\mathrm{AC}$ members have been involved with the risk oversight process materially differed between institutions. One AC chair commented that recent changes in the higher education sector might explain the increased visibility of risk management oversight:

"I think a more sophisticated approach generally in the sector perhaps [in relation] to risk management has driven it. The sector, I think, and institutions within the sector generally living in a riskier environment, has pushed that further up the agenda here with the executive team, [and they] have put together an approach to risk management as a result of that." (AC6)

Relatedly, comments pertaining to the risk oversight process revolved almost entirely around the risk register, and thus confirmed the primacy of this document within the AC's 
deliberations. For example, in two cases, there appears to have been very recent formal consideration of the risk register by the $\mathrm{AC}$ :

“...So recently in the last months or so, the issue of risk management has become far more prominent in the work of the Audit Committee, [such as] the risk register. When we started, it was not a prominent feature, but in the last two years or so, the importance of risk management, identifying risks and managing those risks, has become more prominent. So a fair part of the work of the committee would be looking at the risk register, and seeing whether the identification of risk, and the mitigating factors to handle the risk, timescale for doing that, are adequate, and whether we have views on value and the appropriateness of them... ." (AM2)

"Risk hadn't been part of the Audit Committee at [university name] before. And that's probably interestingly quite controversial. I have come from sectors where it's normal for the audit committee also 'to do risk', but at least one of our members [name] I'm not sure if you are seeing him, he's got a recent background in the insurance industry where risk is forward looking and audit backward looking, so they have a separate risk committee. ...that has been coincidental with actually me thinking that the Audit Committee hasn't really got a grip on the risk part of its portfolio... But we are a bit old fashioned. I mean we have the classic risk register, you know, the highest risk and the mitigation or standard stuff." (AC5)

The emphasis on the corporate risk register, from an AC members' perspective, provides the 'talking points' between AC members and representatives of management, allowing for some coherent sense-making between the parties involved. Management accounts and other financial information - normally the staple of an AC interest's and work - are less prominent in the case of HEIs. For example, only three out of the six ACs regularly have sight of such reports and the $\mathrm{AC}$ members cannot rely on the information therein to draw inferences in relation to financial, operational or strategic risks. Therefore, the main items of discussion arise from the risk register and the external/internal audit reports, as was noticed in one of the meetings we attended. In this specific case, the internal auditor reported on how the institution reviewed its academic offerings and a direct link was made from the risks being reviewed (running 
unprofitable degree schemes as per the register) and the findings of the internal audit report; leading onto some recommendations. More generally, the AC chair below commented upon the review of the [voluminous] risk register, and acknowledged the need for a more detailed understanding of risks:

"Certainly we look at it every meeting and also for one of the ongoing risks, the senior risk owner will come. We take a particular topic; I think we have got 10 corporate high-level risks at the moment, and we take a topic and the risk owner will come and talk to us on that topic. So we have a 20 minute section when we have a particular risk. ...we try and understand a particular risk at a time of the year. ... I am trying to make the Audit Committee interesting, because it can be quite dry I think. So it's actually trying to get a balance of a bit of number crunching and everything, looking at compliance, but also trying to understand everything, particularly as we have two external members who don't come to any other meetings of the University. So, actually to make things come to life for them, I think they can then get an idea of the risks." $(\mathrm{AC} 1)$

However, one of the AC members (AM3) commented at the meeting that risk owners often merely discuss the representation of risk (i.e., as displayed in the risk register or in the presentation by the risk owner) rather than elaborate on the underlying and intrinsic nature of the risks and how the institution intends (if at all) to address them. This is reflected in the following quote in terms of the ceremonial nature of the mitigating actions and the measures that are meant to, respectively, reduce the identified risks and provide a sense of scale to the risks:

"I introduced a risk register when I was chair, because that was the sort of thing you did then. I've since come to think that the risk register is a substitute for thinking about risk! And everybody looks at it and ticks the boxes, and says, 'Oooh, we're doing quite well aren't we?'... And okay,... we've got quite a good risk register now, except we did raise a question about two years ago, saying 'When you put in your mitigating actions, it turns out the risk is just as high at the end of it. That doesn't seem right to us, it ought to mitigate it somehow, otherwise you're not taking the right actions...". (AM3) 
"Now look at what might be considered a lower level risk, for example, 'national reputation'. There has been, there is, a gap between the public perception of the university and what the university would like the public to think of it. Interestingly, [the risk report] tells us that the university has a low acceptable risk [but there is no]... scientifically rational, measureable metric. Well hang on, is that correct?" (AM2)

Furthermore, in most cases, the main interlocutors (senior risk owners) do not attend AC meetings as a matter of course. The 'owner' of the risk register is typically the director of corporate affairs or planning, and in two cases, the deputy vice-chancellor and secretary to the governing board. They addressed most of the questions raised by $\mathrm{AC}$ members; often with a need to defer on a definitive response until further clarification can be sought from the actual risk owner. While the above suggests attempts by the AC to be involved in a more substantive form of oversight involving actual 'risk owners', it also implies that it is in practice difficult for the AC to seek managerial accountability on all major items within the risk register.

The above comments highlight how the risk register has become the embodiment of the risk oversight process; there is a form of functional fixation with the register itself. The AC members effectively seek reassurance that the risk register 'makes sense' and is compatible with external expectations. At the same time, however, some of them do have legitimate qualms as to the substantive nature of the exercise (analysing the risk register) in that (i) it does not appear to spur real debates about risk, (ii) it is simplistic, and (iii) incorporates subjective assessments that are inherently difficult to challenge.

As an example, when reviewing the risk register for one HEI $(\mathrm{F})$, international student recruitment was (rather obviously) a key risk. However, the main mitigating action focused (merely) on reviewing the international recruitment strategy. The AC oversight role was hence more concerned with the deliverable (new) strategy than with directly recommending actions on addressing the negative implications of declining international student recruitment. Relatedly, the use of numerical or vivid colour-coded ratings in the $\mathrm{AC}$ documentation conveyed an 
impression of objectivity, sophistication and control, but in fact implied a great deal of subjectivity, simplification and lack of clarity as to how the organisation will be mitigating risks, which some AC members do find problematic and challenging; but nonetheless chose to 'work with'. Therefore, we would argue that the oversight process of the risk register by the AC incorporated substantive, as well as symbolic features in that it is evident that a great deal of time and effort are expended on considering (and recommending changes to) the contents of the risk register. At the same time, it is arguable whether the AC members actually appreciated the 'reality' beyond the risk register and sought accountability thereof. In effect, the AC's work seems to be limited to ensuring that the register continues to be a well managed and 'reasonable representation' of institutional risk management.

\subsection{Selectivity of risks overseen by the Audit Committee}

One of the recurrent themes from our interactions related to the type of risks being considered (or ignored) by the AC; to a large extent, this is dependent on the organisation's own recording and classifying of specific risks and whether it has adopted a so-called 'bottom-up' or 'top-bottom' approach in terms of collating and managing the risks. In general, a bias towards the oversight of operational risks, as opposed to that of strategic risks, was observed and several interviewees argued that it was not really a judicious use of the AC's time:

"Yes, we've got a beautiful matrix with the percentages next to the likelihood and the percentages next to the impact, and things like that. But they are very operational risks. If you could fit them into that matrix, by my definition, they are very operational. You know, that 'not meeting student recruitment targets', well that's an operational risk. I think what would really benefit us actually is if we had a much more dynamic approach to risk at that committee level, which looks much more at the strategic risks." (FD4)

Several interviewees concur on the limited ability of the AC to be involved in the oversight of the strategic level risks (broadly, the external and longer-term threats to the organisation). There was doubt that $\mathrm{AC}$ members would have the requisite experience and 
expertise to contribute to the organisation's ability to address future challenges. This aspect is symptomatic of the 'expert' role expected of non-executive board members (many of them coming from the corporate or business sector),. This was apparent in one AC, but otherwise it appears that most $\mathrm{AC}$ members were keener to develop an assurance about more tangible and visible operational risks; even if the risk was not particularly important for the HEI.

In one such case (HEI B), a specific operational risk (compliance with technical rules) appeared to dominate the AC's discussions, mainly as a result of the Chair's professional background and expertise in relation to similar issues in a different (non-HEI) context. This fact prompted critical comments from one interviewee on the AC's current over-emphasis on compliance. During the observation stage of the AC meeting, the relevant risk owner privately berated to us that the Chair was attaching too much importance to this particular operational risk, which was seen to be minimal for the institution. Yet, given the Chair's interest in the item and a reluctance to challenge this 'hobby horse' issue, a significant proportion of the meeting was then devoted to the risk implications and mitigating actions. Therefore, while the oversight of the particular risk issue was very detailed and involved internal audit reports and probing of the risk owner (substantive management), the contribution of this exercise to the overall risk oversight was not a very effective one (admittedly from the point of view of the institution).

Furthermore, a notable strategic element of the oversight of risk management is 'risk appetite'. The notion of 'risk appetite' [i.e. an institution's degree of willingness to take (or not take) risks in given areas of activities, such as investment in research, international ventures, estate development, and staffing], appears to have been a regular feature only in three institutions, with others having only just developed policies in this regard:

"We had a Council Away Day in [...], and for the first time in my recollection, we discussed risk appetite at the Away Day. And now that's an annual fixed thing during the Away Day to check that the governors..[...], with the way we structure risk appetite.”( $\mathrm{AC} 2)$ 
While the decision to set a particular risk appetite for given activities and strategies rests with the HEI governing board and not the AC per se, several interviewees recognised the challenges of aligning the risk attitudes of governing board members and management, particularly in a context where $\mathrm{AC}$ and governing board members do not necessarily come from 'risk-taking' backgrounds.

Therefore and in conclusion to this section, the interviews reveal a rather selective level of interest in operational and strategic risks. A minority of ACs, which appear to take a closer interest in the strategic direction of their institution, tended to value the risk oversight process due to the ability for AC members to challenge management on the longer-term risks faced by the institution (e.g., impact of online courses, international trends in higher education, and rationalising investment in building and estates). This was seen to be in line with a substantive form of oversight. However, the majority of the ACs and oversight work focused on the operational aspects and the findings, therefore, reinforced the view that the risk oversight activities are inherently limited by the information and insights provided by management, and further framed by the AC members' own narrow interests or lack of broader expertise. Thus, we would argue that such a form of oversight is more symbolic and more concerned with ensuring (and demonstrating) institutional compliance, rather than enhancing the effectiveness and outcomes of the risk management practices within the institution.

\section{Discussion}

The findings first reveal a proliferation of the risk language and discourses in the oversight of HEIs, which can be mainly ascribed to the UK's HEI regulatory framework, and subsequently to the influence of AC members themselves due to their own expectations that risk management oversight activities 'ought' to be present within the institution. This is a departure from the early evidence on ACs gathered by Dewing \& Williams (1995) and provides an additional insight as to the oversight role of the $\mathrm{AC}$ on risk management in relation to the 
internal audit function (Christopher, 2012). Second, what is peculiar in this case is that the AC is predominantly concerned with the monitoring of processes. This aligns with Power's (2004) reflections on risk management in that there is an increasing expectation that more possible outcomes, such as achieving higher levels of research income, can be regarded "as amenable to human decision and intervention" (2004, p.14). However, it is very likely that higher success rates for research bid will remain outside the realm of institutional and management control. Yet, the risk oversight process on this aspect will continue to be implemented to ensure that this symbolic 'action point' can be 'closed'.

The extent of the oversight process on the ground shows a different and rather mixed picture. While all interviewees concurred that risk is an important part of the AC's role and there was a generally good understanding among the different $\mathrm{AC}$ actors of the relevant guidance, we observed significant variations across the six institutions arising from the following. Firstly, the embedding of risk management and oversight within the institutions differed significantly, from one $\mathrm{AC}$ having implemented such processes more than a decade ago, and another only starting to engage with the practice in a more systematic way. It follows that the level of sophistication, understanding and substantive implementation significantly differed between institutions and ACs alike. For example, the notion of 'risk appetite' appears to have only been a regular feature in three institutions, with the others having only just developed policies in this regard. Secondly, there remains a potentially understandable bias towards operational risk oversight as opposed to strategic risk oversight, and some interviewees argued that this was not necessarily a judicious use of AC time.

The AC's emphasis on overseeing the process rather than the outcomes, together with time constraints, also limited the ability of $\mathrm{AC}$ members to delve into all areas of risk management and whether appropriate mitigating actions were in place on an a priori basis. Therefore, informed by neo-institutional theory and the legitimacy and Ashforth \& Gibbs's (1990) concepts, we contend that the AC's oversight of the risk management function is 
characterised by a mix of symbolic and substantive monitoring activities. From our observations, this state of affairs is not entirely a result of the AC actors' own volition, but also arises from the structural limitations (number of meetings, extent of internal audit work, expertise and knowledge) of what could be understood (and performed) as 'oversight' in this context. So, in line with the neo-institutional perspective, a form of loose coupling developed, whereby risk oversight is largely limited to a public performance of process and compliance activities, which serves the interests of both the AC's and HEI's management in providing a symbolic representation of governance.

Collier \& Woods (2011), and to a limited extent Beasley et al. (2009), also reported evidence of risk management and oversight in for-profit organisations, which were described as being a combination of ceremonial/ritualistic practices (emphasising symbolic management and legitimacy-seeking behaviour) and substantive ones (consistent with agency and/or resourcedependence motives). This theoretical argument is dependent on substantive practices being somewhat 'independent' and unconnected to the symbolic ones, such that the exercise of an agency monitoring or resource-dependence activity would to some extent be 'fully effective' in isolation of other practices, deemed to be symbolic or ritualistic in nature. For example, a thorough oversight of the operational risks would be considered by the above-mentioned authors as a substantive one that is driven by agency or resource-dependence arguments. However, it negates the possibility that overseeing operational risks also involves a shade of symbolism if no concurrent oversight of the strategic risks is carried out. Therefore, it is rather problematic to assign specific oversight actions to a different theoretical underpinning as proposed by Beasley et al. (2009), when some (if not many) of these actions can be inter-related. We instead argue that the maintaining of an organisation's legitimacy remains the central motivation for the AC members to engage in a blend of substantive and symbolic activities. This point would be consistent with Power's (2004) own assertions that the underlying rationale for risk management activities (including its oversight) is not strictly about the management of the primary risks, but 
rather about the more important secondary risk to the organisation - namely its reputational risk. Power et al. (2009) in fact highlighted the centrality of managing reputational risk for universities and there is, in our view, some conceptual closeness (but not equality) between the pursuit of organisational legitimacy and the protecting of an institution's reputation.

\section{Conclusions}

There is a paucity of qualitative research on the role of governance structures in the oversight of organisational risk management. At the same time, the HEI sector has in place fairly detailed governance and risk management/oversight guides prepared by relevant authoritative bodies (e.g., HEFCE, CUC and LFHE), but it is unclear whether these corporatisation-led reforms serve any purpose in this context. Considering a rapidly uncertain environment for UK HEIs and consequently, a greater concern for the risk management functions in HEIs, we question whether ACs are able and ready to monitor and oversee this risk management function. We relied on semi-structured interviews, selected observations of AC meetings, and documentary evidence from six different HEIs address our research questions .

Informed by the institutional theory-led underpinnings of organisational legitimacy and substantive/symbolic legitimation acts, we find that the AC's oversight role can be characterised by a combination of substantive management (questioning risk owners, reviewing risk register, and commissioning audit work) and symbolic management (focus more on operational or peripheral risks and less on strategic ones, process-driven oversight, limited ability to strengthen the monitoring of risk management and mitigation activities, and ensuring compliance). While some of these findings are partly consistent with previous AC-related work in the corporate sector and with risk management studies in the public sector (e.g., Collier \& Woods, 2011; Beasley et al., 2009), this paper contributes to the literature by providing more detailed insights on the AC's actual ability to engage in the oversight of risk management. Risk management practices appear to have been institutionalised in many settings (e.g., Power, 2004) and have led 
to substantial quantitative-led work on the antecedents, determinants and consequences of risk management practices, inclusive of the role of governance structures. Our findings support Power's (2004) view on the limited effectiveness of such practices and arguably the limits of the oversight process by an apex institution, such as a governing board. More specifically, they raise the implication that governing board members, initially enrolled to provide organisational oversight, may be themselves 'captured' and inadvertently driven to play the legitimation 'game' insofar as risk management is concerned. Relatedly, and whilst supportive of the recommendations outlined by Ntim (2018) in terms of improving institutional engagement with, and disclosure of, risk management, our analysis suggests that a word of caution is needed in that traditional conceptions of corporate governance oversight may well encourage more 'loose coupling' and symbolic compliance.

In terms of implications of the findings, HEI policy-makers and regulatory bodies may need to consider whether the relevant guidance on AC composition, diversity, experience and expertise needs to (i) mandate the appointment of risk-management qualified governing board members and, (ii) ensure that they are suitably inducted on risks faced by HEIs (particularly if they come from the private or public sectors). As recently mandated in the UK HEI governance code (Shattock, 2014), periodic council effectiveness reviews (CER) could also formally incorporate a review of the oversight of risk management to identify areas of improvement that ACs should adopt.

Notwithstanding, we acknowledge that our findings are based on a limited access to UK HEIs and there is the possibility that a broader range of case studies may provide more detailed insights into the risk management oversight activities of governing structures. Furthermore, significant environmental turbulence is expected as competitive forces take a stronger hold within the sector and as the UK State seeks to continue to transform HEIs into corporate entities and the sector into a market. The pressures will only increase as UK universities grapple with overpowering strategic risks and threats, such as those posed by the impending so-called 
'Brexit' (the expected exit of the UK from the European Union in March 2019). Our evidence suggests that governing boards and the ACs seem ill prepared to monitor and oversee radical changes. It is within this context of crisis that we see potential for further research to illuminate other areas of governance practice in the sector to spur reflections and appropriate reforms.

\section{References}

Abraham, S., Marston, C., \& Darby, P. (2012). Risk reporting: Clarity, relevance and location. Edinburgh: ICAS.

Arena, M., Arnaboldi, M., \& Azzone, G. (2010). The organizational dynamics of enterprise risk management. Accounting, Organizations and Society, 35(7), 659-675.

Ashforth, B.E., \& Gibbs, B.W. (1990). The double-edge of organizational legitimation. Organization Science, 1, 177-193.

Baker, L. (2006). Observation: A complex research method. Library Trends 55(1), 171-189.

Bailey, B.C., \& Peck, S.I. (2013). Boardroom strategic decision-making style: Understanding the antecedents. Corporate Governance: An International Review, 21(2), 131-146.

Beasley, M.R., Carcello, J.V., Hermanson, D.R., \& Neal, T.L. (2009). The audit committee oversight process. Contemporary Accounting Research, 26(1), 65-122.

Cabedo, J.D., \& Tirado, J.M. (2004). The disclosure of risk in financial statements. Accounting Forum, 28, 181-200.

Cohen, J., Krishamoorthy, G., \& Wright, A.M. (2002). Corporate governance and the audit process. Contemporary Accounting Research, 19(4), 573-594.

Cohen, J., Gaynor, L. M., Krishnamoorthy, G., \& Wright, A. M. (2007). Auditor communications with the audit committee and the board of directors: Policy recommendations and opportunities for future research. Accounting Horizons, 21(2), 165 187.

Collier, P.M. \& Woods, M. (2011). A comparison of local authority adoption of risk management in England and Australia. Australian Accounting Review, 57(21/2), 111-123.

Christoper, J. (2012). The adoption of internal audit as a governance control mechanism in Australian public universities - views from the CEOs. Journal of Higher Education Policy and Management, 34(5), 529-541.

CUC (2008). Handbook for members of audit committees in higher education institutions. London: CUC.

CUC (2009). Guide for members of higher education governing bodies in the UK. London: CUC.

Day, R. \& Woodward, T. (2004). Disclosure of information about employees in the Directors' report of UK published financial statements: substantive or symbolic? Accounting Forum. 28(1). 43-59.

Decoy, R. de P. (2017). To interview or not to interview: A critical approach to assessing endusers' perceptions of the role of 21 st century indigenous interpreters in Peru. The International Journal of Translation and Interpretating Research. 9(1), 36-50.

Dewing, I.P. \& Williams, B.C. (1995). The role of audit committees in UK universities. Managerial Auditing Journal, 10(6), 10-16.

DiMaggio, P., \& Powell, W. W. (1983). The iron cage revisited: Collective rationality and institutional isomorphism in organizational fields. American Sociological Review, 48(2), 147 160.

Gendron, Y., \& Bedard, J. (2006). On the constitution of audit committee effectiveness. Accounting, Organizations and Society, 31(3), 211-239. 
Gendron, Y., Bedard, J., \& Gosselin, M. (2004). Getting inside the black box: A field study of practices in "effective" audit committees. Auditing: A Journal of Practice and Theory, 23(1), 153-171.

Greatbatch, D. (2014). Governance in a Changing Environment: Literature Review. Contemporary Issues in Governance. Leadership Foundation for Higher Education.

Greco, G. (2012). The management's reaction to new mandatory risk disclosure: A longitudinal study on Italian listed companies. Corporate Communications: An International Journal, 17(2), 113-137.

HEFCE (2001). Risk management: A briefing for governors and senior managers. London: HEFCE.

HEFCE (2005). Risk management in higher education: A guide to good practice. London: HEFCE.

LFHE (2009). Getting to grips with risk: Resources for governors of UK universities and higher education colleges. London: LFHE.

Linsley, P.M., Shrives, P.J., \& Crumpton, M. (2006). Risk disclosure: An exploratory study of UK and Canadian banks. Journal of Banking Regulation, 7, 268-282Machold, S., \& Farquhar, S. (2013). Board task evolution: A longitudinal field study in the UK. Corporate Governance: An International Review, 21(2), 147-164.

Marnet, O. \& Soobaroyen, T. (2018). The Quality of Board Decision-Making Processes in Higher Education Institutions: UK and European Experiences. London: LFHE.

Miles M.B., Huberman A.M. \& Saldaña, J. (2014). Qualitative Data Analysis. A Methods Sourcebook. Sage. London.

Mulhall, A. (2003). In the field: Notes on observation in qualitative research. Journal of Advanced Nursing, 1(3), 306-313.

Ntim, C.G. (2018). Governance and risk disclosure practices in UK higher education institutions in an era of austerity and reform. London: LFHE

Ntim, C.G., Soobaroyen, T., \& Broad, M.J., (2017). Governance structures, voluntary disclosures and public accountability: The case of UK higher education institutions. Accounting, Auditing \& Accountability Journal, 30(1), 65-118

Ntim, C.G., Lindop, S., Osei, K.A., \& Thomas, D.A. (2013). Corporate governance and risk reporting in South Africa: A study of corporate risk disclosures in the pre- and post2007/2008 global financial crisis period. International Review of Financial Analysis, 30, 363383.

O'Dwyer, B., (2004). Qualitative data analysis: Exposing a process for transforming a "messy" but "attractive nuisance", in C. Humphrey and B. Lee (eds). A Real Life Guide to Accounting Research: A behind the scenes view of using qualitative research methods. Amsterdam: Elsevier.

Palermo, T. (2014). Accountability and expertise in public sector risk management: A case study. Financial Accountability \& Management, 30(3), 322-341.

Parker, L.D. (2011). University Corporatisation: Driving redefinition. Critical Perspectives on Accounting, 22, 434-450.

Parker, L. D. (2013). Contemporary university strategising: the financial imperative. Financial Accountability \& Management, 29(1), 1-25.

Parker, L.D. \& Roffey, B.H. (1997). Back to the Drawing Board: Revisiting Grounded Theory and the Everyday Accountant's and Manager's Reality. Accounting, Auditing and Accountability Journal, 10(2), 212-247.

Patton M.Q. (2002). Qualitative research \& evaluation methods. Sage. London.

Power, M. (2004). The risk management of everything: Rethinking the politics of uncertainty. London: Demos.

Power, M., Scheytt, T., Soin, K., \& Sahlin, K. (2009). Reputational risk as a logic of organizing in late modernity. Organization Studies, 30(2-3), 301-324. 
Saldaña J. (2013). The coding manual for qualitative researchers. Sage. London.

Schofield A (2013). Getting to Grips with Being a New Governor. London: Leadership Foundation for Higher Education (LFHE).

Scott, P. (1995). The meanings of mass higher education. McGraw-Hill Education (UK).

Shattock, M. (2013). University governance, leadership and management in a decade of diversification and uncertainty. Higher Education Quarterly, 67(3), 217-233.

Shattock, M. (2014). University governance in the UK: Bending the traditional model. International trends in university governance: Autonomy, self-governance and the distribution of authority, 127-144.

Soobaroyen, T., \& Mahadeo, J.D (2008). Selective compliance with the corporate governance code in Mauritius: Is legitimacy theory at work?, Corporate Governance in Less Developed and Emerging Economies (pp. 239-272). Emerald Group Publishing Limited.

Soobaroyen, T., Broad, M.J., \& Ntim, C.G. (2014). The role and effectiveness of audit committees in UK higher education institutions. London: LFHE.

Spira, L.F., \& Page, M. (2003). Risk management: The reinvention of internal control and the changing role of internal audit. Accounting, Auditing \& Accountability Journal, 16(4), 640661.

Suchman, M.C. (1995). Managing legitimacy: Strategic and institutional approaches. Academy of Management Review, 20, 571-606.

Taylor, M. (2013). What is good university financial management? Perspectives: Policy and Practice in Higher Education, 17(4), 141-147.

Tolbert, P. S., \& Zucker, L. G. (1983). Institutional sources of change in the formal structure of organizations: The diffusion of civil service reform, 1880-1935. Administrative science quarterly, 22-39.

Turley, S. \& Zaman, M. (2007). Audit committee effectiveness: Informal processes and behavioural effects. Accounting, Auditing, \& Accountability Journal, 20(5), 765-788.

Woods, M. (2009). A contingency theory perspective on the risk management control system within Birmingham City Council. Management Accounting Research, 20(1), 69-81. 


\begin{tabular}{|c|c|c|}
\hline UK HEI & Interviewees & $\begin{array}{l}\text { Audit committee meeting } \\
\text { observation }\end{array}$ \\
\hline A (pre-1992)* & $\begin{array}{l}\text { Member of audit committee. } \\
\text { Finance director. } \\
\text { Internal auditor. } \\
\text { Chair of audit committee. }\end{array}$ & $\begin{array}{l}\text { Partial audit committee 'public' } \\
\text { meeting with some access to } \\
\text { documents (approximately one } \\
\text { hour). }\end{array}$ \\
\hline B (pre-1992) & $\begin{array}{l}\text { Member of audit committee. } \\
\text { Chair of audit committee. } \\
\text { Internal auditor. } \\
\text { Finance director. }\end{array}$ & $\begin{array}{l}\text { Partial audit committee 'public' } \\
\text { meeting with some access to } \\
\text { documents } \\
\text { (approximately one hour). }\end{array}$ \\
\hline C (pre-1992) & $\begin{array}{l}\text { Chair of audit committee. } \\
\text { Finance director. } \\
\text { Chief executive officer. } \\
\text { Member of audit committee. }\end{array}$ & No meeting attended. \\
\hline $\mathrm{D}($ post-1992)* & $\begin{array}{l}\text { Finance director. } \\
\text { Chair of the audit committee. } \\
\text { Member of audit committee. }\end{array}$ & No meeting attended. \\
\hline E (post-1992) & $\begin{array}{l}\text { Finance director. } \\
\text { Internal auditor. } \\
\text { Member of audit committee. } \\
\text { Chair of audit committee. }\end{array}$ & No meeting attended. \\
\hline $\mathrm{F}$ (post-1992) & $\begin{array}{l}\text { Finance director. } \\
\text { Chair of finance committee (previously } \\
\text { audit committee member). } \\
\text { Chair of audit committee. } \\
\text { Internal auditor. }\end{array}$ & $\begin{array}{l}\text { Full audit committee meeting, } \\
\text { inclusive of private meeting of } \\
\text { members and full access to } \\
\text { documents (approximately } 2.5 \\
\text { hours). }\end{array}$ \\
\hline \multicolumn{3}{|c|}{$\begin{array}{l}\text { For the sake of confidentiality and anonymity, all identifying comments (e.g., names of individuals, organisations and } \\
\text { departmental titles) have been removed from the quotes used in this study. Quotes are coded on the basis of the } \\
\text { interviewee's role, namely AC Chair (AC1, AC2, etc.), AC Member (AM1, AM2, etc.), Finance Directors (FD1, FD2, } \\
\text { etc.), Internal Auditor (IA1, IA2, etc.), and other university executives (EX1, EX2, etc.). There is no reference to the } \\
\text { institution per se in this coding system to avoid the possibility that interviewees (who have been asked to vet the } \\
\text { transcript of the interviews) could indirectly identify quotes by other interviewees from the same institution (coded as A. } \\
\text { B. C, etc.). }\end{array}$} \\
\hline
\end{tabular}




\section{Appendix 1 - Outline interview questions}

These questions served as a basis to dwell further on different aspects of the audit committee's work, and how the AC monitors the HEI's risk management process. The emphasis of the questions changed depending on the profile of the interviewee (e.g. AC Chair. AC member, or executive).

1. What do you perceive as the role of audit committee general and in relation to risk management in particular?

2. Has the codes and guidance provided by HEFCE / CUC / Leadership Foundation or other bodies been made available and have they been useful in setting out the AC's role and expectations? If so, in what ways?

3. What would be the typical process of an AC meeting? What would be the typical performance reports (use of KPIs, risk register, internal/external audit reports if applicable) circulated in the meeting

4. Provide risk management examples of interactions between finance executives and the $\mathrm{AC}$, and of interactions between main board and $\mathrm{AC}$ members

5. To what extent is questioning and a critical assessment of the answers by the HEI managers a key part of the role? How important is risk management?

6. Is the composition of the $\mathrm{AC}$ sufficient and adequate for the assigned tasks? If so (or not), why?

7. Expertise and knowledge in accounting, risk and financial matters is generally expected of AC members? Is this always beneficial for an AC to be effective? Why?

8. In practice, is the audit committee perceived to be a key or influential part of the board? Does it initiate debates within or outside board meetings? Why?

9. What is the extent to which the executive subsequently addressed issues raised in earlier meetings? 